\title{
Influence of Spatial Layout of Residential Buildings on Sedentary Behaviour of Residents in Enugu, Nigeria
}

\author{
Austin M. Ezezue ${ }^{1, *}$, Eziyi O. Ibem ${ }^{2}$, Francis O. Uzuegbunam², Chinwuba O. Odum², \\ Monoyoren E. Omatsone ${ }^{3}$ \\ ${ }^{1}$ Department of Architecture, Nnamdi Azikiwe University, Awka, Anambra State, Nigeria \\ ${ }^{2}$ Department of Architecture, University of Nigeria, Enugu Campus, Enugu State, Nigeria \\ ${ }^{3}$ Department of Architecture, Ambrose Alli University, Ekpoma, Edo State, Nigeria
}

Received March 26, 2021; Revised May 11, 2021; Accepted June 15, 2021

\section{Cite This Paper in the following Citation Styles}

(a): [1] Austin M. Ezezue, Eziyi O. Ibem, Francis O. Uzuegbunam, Chinwuba O. Odum, Monoyoren E. Omatsone, "Influence of Spatial Layout of Residential Buildings on Sedentary Behaviour of Residents in Enugu, Nigeria," Civil Engineering and Architecture, Vol. 9, No. 4, pp. 1123-1136, 2021. DOI: 10.13189/cea.2021.090414.

(b): Austin M. Ezezue, Eziyi O. Ibem, Francis O. Uzuegbunam, Chinwuba O. Odum, Monoyoren E. Omatsone (2021). Influence of Spatial Layout of Residential Buildings on Sedentary Behaviour of Residents in Enugu, Nigeria. Civil Engineering and Architecture, 9(4), 1123-1136. DOI: 10.13189/cea.2021.090414.

Copyright $\bigcirc 2021$ by authors, all rights reserved. Authors agree that this article remains permanently open access under the terms of the Creative Commons Attribution License 4.0 International License

\begin{abstract}
Sedentary lifestyle is a major cause of several non-communicable killer diseases globally. However, there is limited understanding of how the design and planning of residential buildings can help in curbing sedentary lifestyle among urban population in the developing countries. This research investigated the spatial layout of residential buildings and its influence on sedentary lifestyle of the occupants in Enugu metropolis in southeast Nigeria. A questionnaire survey of 400 residents and evaluation of the active design features of the floor plans of their residential buildings were conducted in the study area. The data were analysed using descriptive statistics, ANOVA, Duncan multiple comparison test, and thematic content analysis. The residential buildings were found to have the traditional house and western style house layouts. Although the results indicated that residents spent about $90 \%$ of the time at home on sedentary activity, those living in buildings with traditional house layout were found to spend the least time on sedentary activity compared to those in dwelling units with western style house layout pattern. The results of Duncan multiple comparison test revealed that residents in house layouts where the conveniences are separated from the sleeping place or lounge, spent significantly lower time on sedentary activity such as sitting, while the reverse was the case for light activity like standing. The findings of this research are instructive in revealing that when it comes to active design, the traditional house layout pattern appears to have
\end{abstract}

advantage over the modern or western style. It is therefore recommended that to achieve residential design that promotes physical activity among occupants, architects and other professionals involved in housing development should consider the adoption of the traditional layout concept in the design of future homes in the study area and beyond.

Keywords Active Design, Enugu, Physical Activity, Residential Buildings, Sedentary Behaviour, Survey

\section{Introduction}

Knowledge on the relationship between human health and the indoor environment has continued to evolve as evidence has continued to accumulate on how the lack of physical activity has become a major contributor to some chronic and non-communicable diseases across the world. This has become more pronounced now than before as studies have shown that a high proportion of urban residents in different regions of the world spend around $90 \%$ of their time indoors either at home or at work [1-3]. The advent of COVID-19 pandemic and the lock down associated with it have exacerbated sedentary lifestyle among urban population across the globe. In fact, a 
previous study by Wolin et al. [5] has established that adults, whether at home, work or school spend approximately between $50 \%$ and $60 \%$ of their day in activities that require low intensity movement; and are thus at risk to various ailments and health conditions associated with sedentary lifestyle.

Sedentary behaviour (SB) or lifestyle has been described as the lack of physical activity or not being able to attain a criterion level of activity [6]. According to Waters et al. [7], sedentary lifestyle is synonymous with long period of sitting or lying down, and other low metabolic activities. Parry and Straker [8] have noted that sedentary lifestyle is emerging in the western world as an important risk factor associated with poor health and high mortality, while others have also associated sedentary lifestyle with obesity and death $[9,10]$, increase in cardiovascular diseases and cancer [11,12] and reduced life expectancy [13]. In a developing country like Nigeria, where many people live in residential homes with poor indoor air quality [1,4], there is a growing concern over public health issues associated with sedentary behaviour. The World Health Organisation [14] had reported the existence of a huge burden of cardiovascular disease (CVD) in Nigeria resulting from sedentary lifestyle and other chronic diseases. Some studies [15-17] have also shown that this situation can been linked to the adoption of western architectural styles, reduced physical activity and inappropriate dieting. In view of the foregoing, authors have argued that the health risk directly or indirectly associated with sedentary behaviour has informed increasing research on architectural design interventions for curbing sedentary lifestyle among the population [18].

There is a growing body of research showing that the design of the built environment to support daily physical activity otherwise known as active design, can bring positive health outcomes for children and adults [19-21]. Active design impacts on human health by helping building occupants integrate regular physical activity into their daily life unconsciously [22,23]. Based on the principles of active design, it seems feasible that layout of homes and, in particular, the distance required to reach key destinations in residential buildings such as bed rooms, living rooms, kitchens, washrooms and others could affect both occupants' levels of movement and time spent sitting or lying $[24,25]$. For example, the Center for Active Design [26] had noted that having staircase, appealing, supportive walking routes such as lobbies and corridors and location of functions within buildings to encourage walking can promote physical activity and the health of occupants. In their support of advantages of physical activity in homes, previous studies have also established that regular physical activity has a strong link with decreased cardiovascular disease and comorbidities, and reduced risk of mortality [27,28].

In spite of growing awareness that design of the built environment plays an important role in supporting or suppressing a person's level of physical activity [29], it is observed that research on how residential buildings can curb sedentary lifestyle among occupants is limited. Most of the existing studies $[30,31,32,33]$ have tended to focus more on architectural design and spatial planning strategies to improve physical activity in office environment. In Nigeria for example, Oyeyemi et al. [17] investigated sedentary life style and health of occupants of buildings generally, while a most recent study examined architectural design interventions for sedentary behaviour among workers in office buildings in Enugu metropolis [18]. However, none of these studies specifically examined spatial design features of residential buildings and how these have influenced the sedentary behaviour of their occupants. As result, there is a gap in knowledge on the extent to which the spatial layout of residential buildings can influence residents' sedentary behaviour.

Therefore, the aim of the current research was to examine the spatial layout of residential buildings and its influence on sedentary lifestyle of the occupants in Enugu metropolis in southeast Nigeria. This is premised on the need to improve understanding of the architectural design strategies that can help in curbing sedentary behaviour in residential environments. The research was guided by two research objectives, namely 1) to identify the predominant spatial layout patterns of residential buildings in selected neighbourhoods of Enugu metropolis, Nigeria; and 2) to examine the influence of the different spatial layout of residential buildings on sedentary behaviour of the occupants in the study area. In the context of this study, spatial layout refers to the location of spaces, distance and interrelationship between them, which determines the size of floor plans of the buildings. This research adds to scientific knowledge by identifying the specific architectural design strategies that can increase regular physical activity such as active movement and recreation in occupants' of residential buildings, especially in the tropics. In the light of this, the novelty of this research lies in its potential to uncover how domestic architecture can contribute to combating sedentary lifestyle and the attendant health consequences among urban population in the study area and beyond.

\section{Literature Review}

\subsection{Active Design in Residential Buildings}

The understanding that the way the built environment is planned and designed can promote healthy environments and behaviour as well as mitigate adverse individual and public health outcomes has contributed to the emergence of active design practice [34]. The review of literature reveals that the evolution of active design, which seeks to promote physical activity and health through spatial 
planning and architectural design can be attributed to the City of New York [35]. This is in tandem with the concept of humanistic design that takes people's behavioral pattern into full consideration in designing and planning spaces that conveniently support people of different lifestyles. Burney and Clafin [23] opined that it is increasingly evident that design needs to play a key role in reducing sedentary behaviour by adopting design concepts that compel people to be active. It was on this premise that Nicoll [22] noted that the overall goal of active design practice is to create built environments that encourage people to be more physically active whether at home or at work. The totality of environment that promotes physical activity has been described as a subset of broadly defined physical environment, which encompasses built and natural environments [36]. It has been noted that such environment can be achieved through appropriate and deliberate policies that influence design and planning concepts that enhance the opportunities to engage in physical activity in recreation, transportation, work, and household activities [37].

Notably, the contributions of several authors on the indoor built environment, particularly at the home, occupational and educational settings have further buttressed the need for a change of activity levels of people of all ages [38,39]. Moreover, the submission by Smith, Ekelund and Hamer [40] that people need to sit less, move around more and preferably move more energetically, invariably means that a variety of aspects of the indoor environment could potentially play an important role in active design. Nicoll [22] further explained that achieving active design entails making changes in urban, community and building design, with the overall goal of providing everyone the opportunity to engage in daily physical activity required to stay healthy and remain productive. The author also identified the common active design strategies to include 1) the use of stairs, 2) providing options for parents to be active while supervising their children's play at home 3 ) having secure and environmentally protected bike storage at homes and in workplaces, 4) engaging physical strategies that allow people walk to shops, services and recreational facilities from their homes and workplaces and 5) provision of spaces that encourage physical activity at home. In line with the foregoing, Brookfield et al. [41] concluded that in residential buildings, the having steps/staircases, space within the home, and the location and form of facilities, fixtures and fittings are key features determine the extent to which homes can aid or impede a more active and less sedentary lifestyle among the occupants. Therefore, these features have been used to classify the spatial layouts of residential buildings when it comes to active design [38]. In line with this, the investigation of the spatial layouts of residential buildings in the study is based on the aforementioned features.

\subsection{Nexus between Architectural Design and Physical Activity}

The review of extant studies has also revealed that the built environment and structural design strategies can impact human behaviour and cause people to move and sit-less $[20,42]$. This prompted authors to infer that the way the environment where people live, work and play is planned, designed and constructed can encourage or discourage physical activity such as movement and mobility [35]. Physical activity is arguably more place-dependent because while some places such as playgrounds, fitness clubs and stairs are physical activity-friendly by nature or design more than compact homes, theatres, and classrooms [36]. Following from this, the nexus between architectural design and physical planning and sedentariness as well as its health implications calls for an in-depth study, most particularly, as it relates to the role of design in moderating the level of physical activity and sedentary behavior in the population.

By implementing active design strategies, through spatial design and planning of residential environment, architects, planners, and building professionals can help increase physical activity and combat the growing incidences of obesity and related chronic diseases, such as diabetes, heart disease, strokes, and certain types of cancer $[22,43]$. This was corroborated by the Centers for Disease Control and Prevention [44] which noted that small amounts of physical activity in daily routines in homes may be effective in checkmating some chronic and non-communicable diseases. On their part, Zimring et al. [45] explained that building design and construction practices that reflect active design principles can influence sedentary lifestyle in homes. Generally speaking, behaviour settings and their influence on physical activity and sedentary choices have been articulated by Owen, Salmon, and Fotheringham [46]. These authors were of the view that flexibility and adaptability in design, as opposed to formulaic prescriptions, may be more appropriate in ensuring that design needs, which are constantly changing over time or as different people continue to use the building. With these in mind, designers, owners and managers of buildings usually look up to the built environment research community to provide solid evidence on the characteristics of places in which physical activity and non-sedentary behaviour are encouraged [33].

As it relates to home environment, some authors have shown that living in a residential environment that has walkable, connected sidewalks and inter-sections and a large density of destinations can improve the level of physical activity among adults [47,48]. Further, the Center for Active Design [26] and the UK's Design Council [38] have articulated active design guidelines that seek to address health concerns associated with the lack of physical activity in indoor environments. These authors 
have explained that for indoor environments, the inclusion of stairs and location of some building functions to encourage brief bouts of walking were the key active design interventions. This implies that the location of spaces and the relationship between them could potentially play a more significant role in reducing sedentary lifestyle. This line of thinking tends to suggest that several aspects of the indoor environment could potentially play important roles in ensuring active design through the ordering of spaces and the use of circulation elements to encourage constant movement and mobility. Drawing from the foregoing, indoor environment could be designed and planned in such a way that users are compelled to sit less and move around [40]. What this means is that the level of physical activity among occupants of residential buildings is among others, a function of the spatial layout of the plans as well as the interrelationship of the spaces with the buildings. This is one aspect the current study is interested in and sought to provide solid empirical evidence on.

\section{Materials and Methods}

Enugu, the study area, is part of the capital territory of Enugu State which was created on August 27, 1991. It is located on the latitude $6^{\circ} 30^{\prime} \mathrm{N} 7^{\circ} 30^{\prime} \mathrm{E}$ [49]. With a population of about 5,590,513 million people [50], Enugu State has a population density of about two and half times the national average of $2.8 \%$. Enugu has a relatively good climate, sitting at about 223 meters above sea level, and the soil is well drained, with a mean daily temperature of $26.7^{\circ} \mathrm{C}$ and the average annual rainfall of around $2,000 \mathrm{~mm}$ [51]. Other weather conditions affecting the city include harmattan, a dusty trade wind lasting a few weeks of December and January [52]

The survey research design was adopted for the study. This involved both the administration of questionnaire and observations. The population of study comprised residents and their residences in selected residential neighbourhoods in Enugu metropolis. Enugu metropolis has twenty-four main residential neighbourhoods and some minor ones as shown in Figure 1.

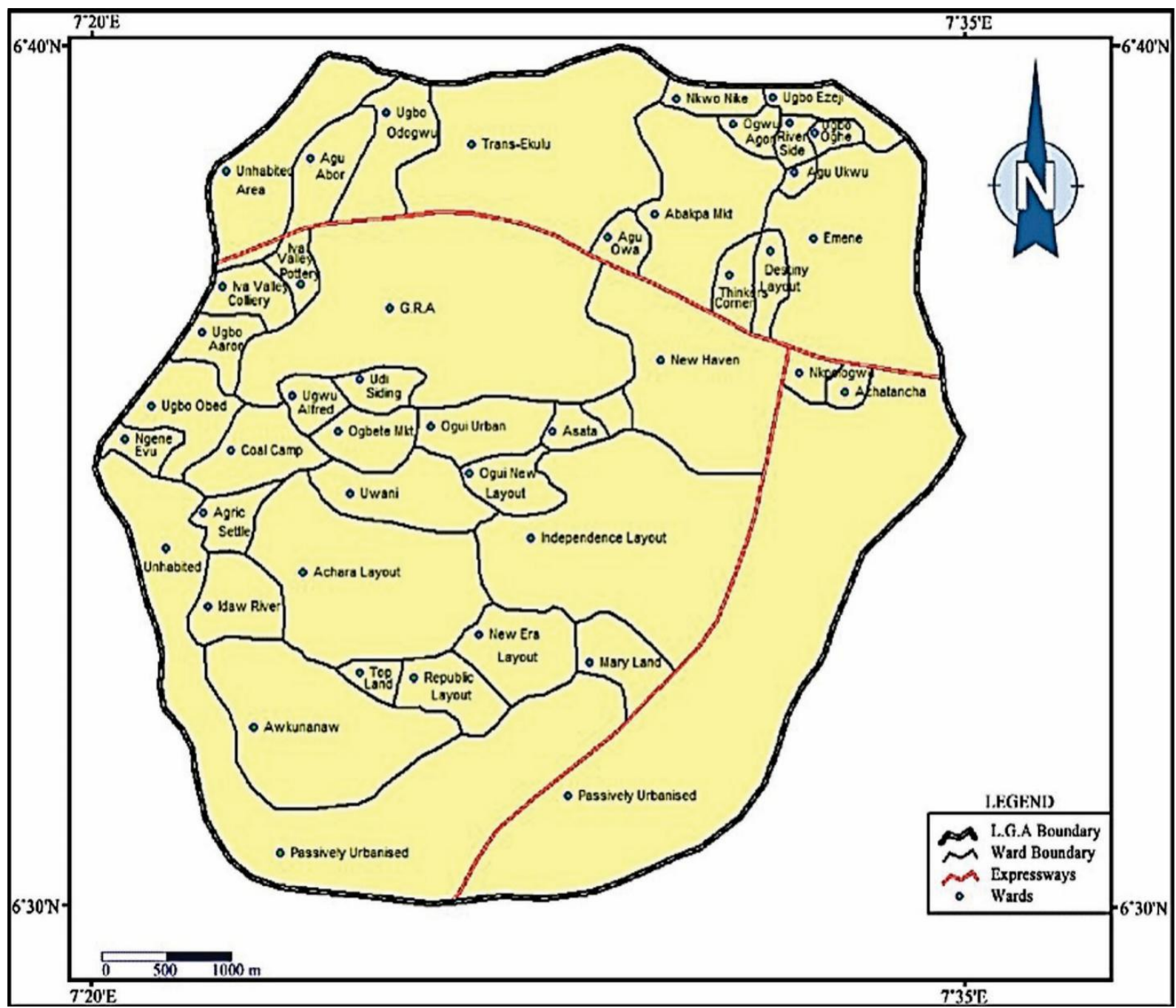

Source: Ezenwaji, Nzoiwu \& Eduputa [53]

Figure 1. Major and minor residential neighbourhoods in Enugu Metropolis 
The major residential neighbourhoods were categorized into three residential densities as shown in the Table 1. Three neighbourhoods were conveniently selected from each of the three density groupings, namely: high, medium and low as shown in Table 1 . The residential buildings were stratified into seven residential house prototypes based on their spatial layouts. The strata include 1) block of flats (Figure 3) 2) semi-detached maisonette without garage (Figure 4) 3) semi-detached maisonette without garages (Figure 5) 4) detached maisonette with garage (Figures 6) and 5) semi-detached bungalow with garage (Figure 7).

Table 1. The residential densities in Enugu metropolis and neighbourhoods selected for study

\begin{tabular}{|c|c|c|}
\hline High Density & Medium Density & Low Density \\
\hline Nike* & Achara* & Aria layout* \\
\hline Asata & Awkunanaw* & City layout \\
\hline Asata Camp & Idaw river layout & G.R.A \\
\hline Ogbete* & Maryland & $\begin{array}{c}\text { Independence } \\
\text { layout* }\end{array}$ \\
\hline Ogui & New era & Republic Layout \\
\hline Ogui New & New Haven* & River side \\
\hline Iva valley & Secretariat quarters & Tinkers corner \\
\hline Uwani* & Udi siding & Trans Ekulu* \\
\hline
\end{tabular}

* Selected neighbourhoods from existing densities in Enugu

Due to the absence of accurate data on the actual number of residents in the identified strata of house types identified for investigation in the study area upon which adequate sample size can be obtained for the survey, the sample size was determined using the Cochran's [54] formula for infinite population as shown in Equation 1

$$
\mathrm{n}_{0}=\mathrm{Z}^{2} \mathrm{pq} / \mathrm{e}^{2}
$$

Where $\mathrm{n}_{0}$ is the minimum sample size, $\mathrm{Z}$ is the critical value, which is at $95 \%$ level of confidence, and in this case, it is 1.96; $p$ is $0.5 ; \mathrm{q}=1-\mathrm{p}$, while $\mathbf{e}$ is the desired level of precision in the statistical estimates, that is $5 \%$. The choice of $95 \%$ confidence level was because the authors assumed maximum variability in the sedentary behaviour of the research population in the study area. Based on these, the minimum sample size calculated was 385 residents. However, 39 additional residents, which represent $10 \%$ of the calculated 385 were added to this figure to take care of non-responses. This translated to a minimum sample size of 424 residents.

The key data collection instrument used in this research was a structured questionnaire designed by the researchers. The questionnaire was divided in two sections: A and B. Whereas section A was used to gather data on the personal profiles of the residents in the different house layouts selected in the nine residential neighbourhoods selected for the study, session B was used to collect data on the level of physical activity and sedentary lifestyle of the residents as well as the spatial, fittings and furniture features of the individual housing units. In gathering data on the residents' levels of physical activity, occupants of the houses were asked to indicate the time they spend sitting before going to bed, standing before bed and time spent at home performing moderate activity such as house chores. The data on spatial features of their dwelling units were collected by asking the residents to choose from the five options the ones that best describe their homes: 1) sleeping space, TV lounge/reading, in-suit toilet/dressing/wardrobe, with in-house private lounges, breakfast nooks / kitchenette 2) sleeping space, lounge, in-suit toilet/ ward robe 3) sleeping space, in-suit toilet, wardrobe 4) sleeping space, wardrobe, grouped convenience 5) sleeping space, separated from bath and $\mathrm{WC}$; non-purposive wardrobe.

In the selection of respondents for the survey, household heads or adult representatives were purposively selected for the administration of the questionnaire. The criteria employed in the selection of residential buildings were participants were drawn were based on the building types, that is those buildings having similar features being in the same strata. Following from this, stratified sampling technique was used in the selection process. This was to ensure that all building types identified were adequately presented in the sample. Other criteria used were the possibility of accessibility, construction materials and willingness to participate in the survey. Totally, 424 copies of the questionnaire were administered to residents of the seven different housing types identified. A copy of the questionnaire was given by hand to the household head or an adult member of the family found in the dwelling units during the survey. However, 400 copies of the questionnaire were retrieved. This translates to a response rate of $94.35 \%$. The data on spatial layouts of the housing units were complimented by physical observations of the floor plans of the buildings made during the survey. These were documented using sketch pads and pencils and later transformed to AUTOCAD drawings.

The data collected via the questionnaire were analysed using descriptive statistics to show the frequency and percentage distributions of the personal profiles of the participants in the survey. In addition, the comparison of means was done using ANOVA and Duncan multiple comparison test, while the data collected through physical observations of the floor plans of the buildings were analysed using thematic content analysis. The results are presented using texts tables and unscaled architectural drawings.

\section{Results and Discussion}

\subsection{Personal Profile of the Participants in the Survey}

The descriptive analysis of the personal profiles of the research participants reveals that more males than females 
participated in the survey (Table 2). The results also show that a majority (86.9\%) of the participants were between the age bracket of 25 years and 54 years and around $96.5 \%$ of them had a minimum academic qualification of HND or a bachelor degree as shown in Table 2. Furthermore, the results also show that a high majority $(74.7 \%)$ of the participants lived in buildings having traditional house layout, while $25.3 \%$ lived in buildings designed based on the modern (western) house layout. In addition, many $(58.6 \%)$ of the buildings were more than 6years old and $54.5 \%$ of the respondents had been living the buildings for over 5 years (Table 2 ).

The results in Table 2 generally show that although only adults of 18years and above were selected for the survey, some of the participants were below 18years of age. This is either because those who were original given copies of the questionnaire to fill delegated the task to youngers persons in their families/households or those adults who were given copies of the questionnaire were not sincere in indicating the actual range of their years This is one of the challenges encountered in a questionnaire survey in the study area. In any case, it is evident from the results that participants in the survey are residents within the active population and are highly educated, and hence are literate enough to understand the contents of the questionnaire and answer the questions accordingly. The results also indicate that more of the buildings were designed based on the traditional house layout concept and the residents had lived in the residences for a reasonable length of time; and thus understand the spatial layouts and other features of their dwelling units.

Table 2. Personal profile of research participants

\begin{tabular}{|c|c|c|}
\hline & Frequency & Percent \\
\hline \multicolumn{3}{|l|}{ Sex } \\
\hline Male & 225 & 56.3 \\
\hline Female & 175 & 43.8 \\
\hline \multicolumn{3}{|l|}{ Age range } \\
\hline $15-24$ & 49 & 12.3 \\
\hline $25-34$ & 92 & 23.0 \\
\hline $35-44$ & 148 & 37.1 \\
\hline $45-54$ & 107 & 26.8 \\
\hline 55 and above & 4 & 1.0 \\
\hline \multicolumn{3}{|l|}{ Educational Qualification } \\
\hline O' Level GCE/SSCE/NABTEB & 7 & 1.8 \\
\hline National Diploma./National Certificate of Education & 7 & 1.8 \\
\hline Higher National Diploma (HND)/ Bachelor degree & 168 & 42.0 \\
\hline Higher degree & 218 & 54.5 \\
\hline \multicolumn{3}{|l|}{ Building type occupied } \\
\hline Flat system & 46 & 11.5 \\
\hline Traditional building & 299 & 74.7 \\
\hline Maisonette & 19 & 4.8 \\
\hline Bungalow & 36 & 9.0 \\
\hline \multicolumn{3}{|l|}{ Age of building occupied } \\
\hline No Response & 8 & 2.0 \\
\hline $1-5$ years & 33 & 8.3 \\
\hline 6-25years & 125 & 31.3 \\
\hline More than 25years & 109 & 27.3 \\
\hline Not sure & 125 & 31.3 \\
\hline \multicolumn{3}{|l|}{ Duration of stay in the building } \\
\hline 10years + & 124 & 31.0 \\
\hline 6-10years & 94 & 23.5 \\
\hline $2-5$ years & 114 & 28.5 \\
\hline Under 2years & 60 & 15.0 \\
\hline Others & 8 & 2.0 \\
\hline
\end{tabular}




\subsection{Spatial Layout Characteristics of the Residential Buildings Investigated}

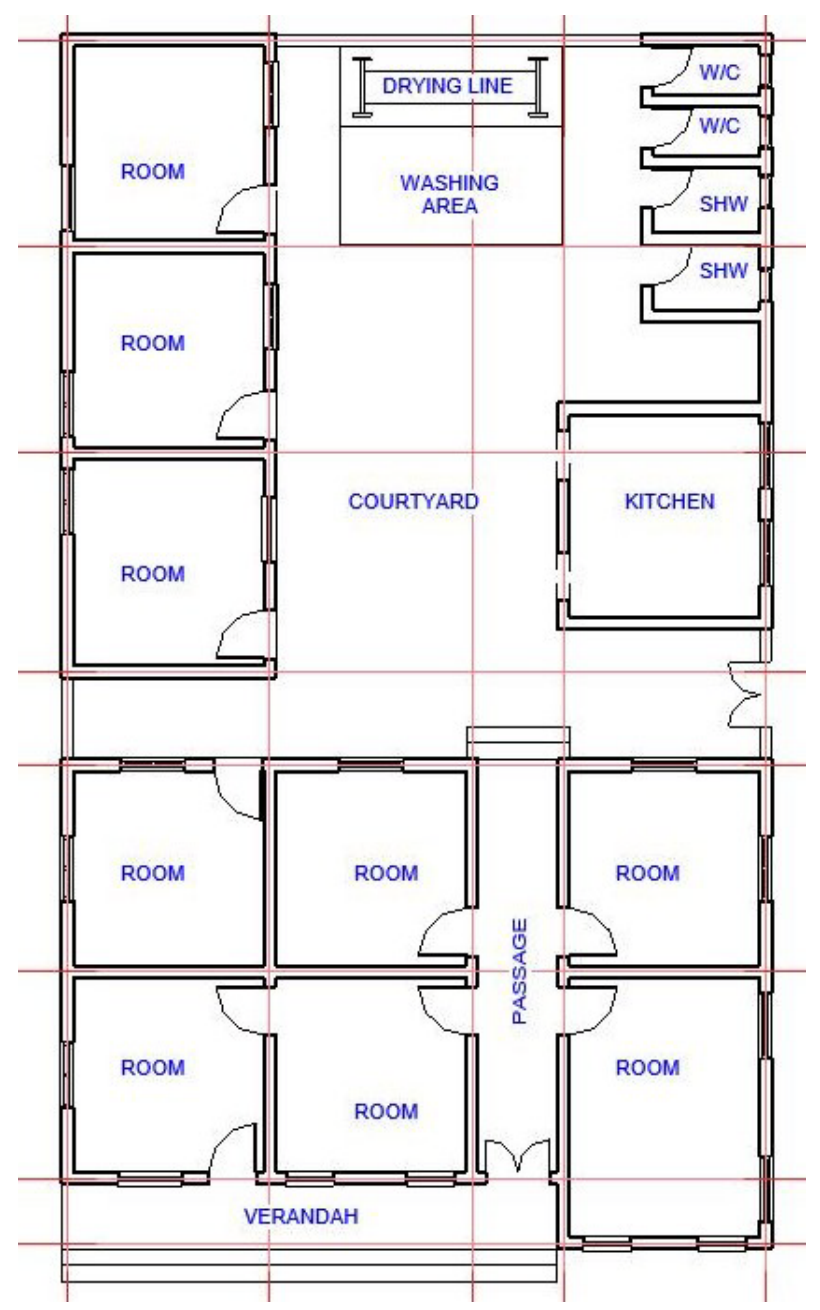

Figure 2. Floor plan of tenement building based on Igbo Traditional house layout

One of the objectives of this research was to identify the spatial layouts of the residential buildings in the study area where respondents in the survey were selected from. Based on this, the houses identified were put into two predominant categories: those designed and built based on the traditional concept and those based on modern (western) housing concept. The buildings with the traditional house layout pattern were found to be 1- storey in height. The houses were characterized by rectangular plans. The floor plan of a typical tenement building designed based the traditional Igbo architecture of the South-eastern geopolitical zone of Nigeria is shown in Figure 2.

Typically, the layout comprises several rooms with verandah and corridor core areas for families or households who are from the same family. It can also be occupied by renters who share common facilities such as kitchens, toilets and bathrooms. In larger buildings designed and built based on this tradition concept, there are verandahs at the front of the houses with rooms built round an inner courtyard separating public from private spaces. In such cases, the kitchens, toilets and bathrooms are separated from the rooms using courtyards and corridors (see Figure 2). The courtyard usually serves as space for social interactions among the occupants and for recreational activities by children and adults; and thus helps to promote physical activity. These features are in line with those identified by Aniako [54] as the common features of Igbo traditional house layout.

The modern or western style house layout pattern was found in the form of block of flats (Figure 3), semi-detached maisonette without garage (Figure 4), semi-detached maisonette without garages (Figure 5), detached maisonette with garage (Figures 6) and semi-detached bungalow with garage (Figure 7). Although these housing types were designed based on the western style, their floor plans appear relatively homogenous in physical characteristics with differences in mass and spatial characters. The interior spaces appear to be well "knitted" together, and are usually tight and compact in design, which can encourage less physical activity and promote sedentary behaviour. According to previous authors, this is because the designs of these buildings are blend of western ideas and concepts on entirely different contexts $[1,55]$. 


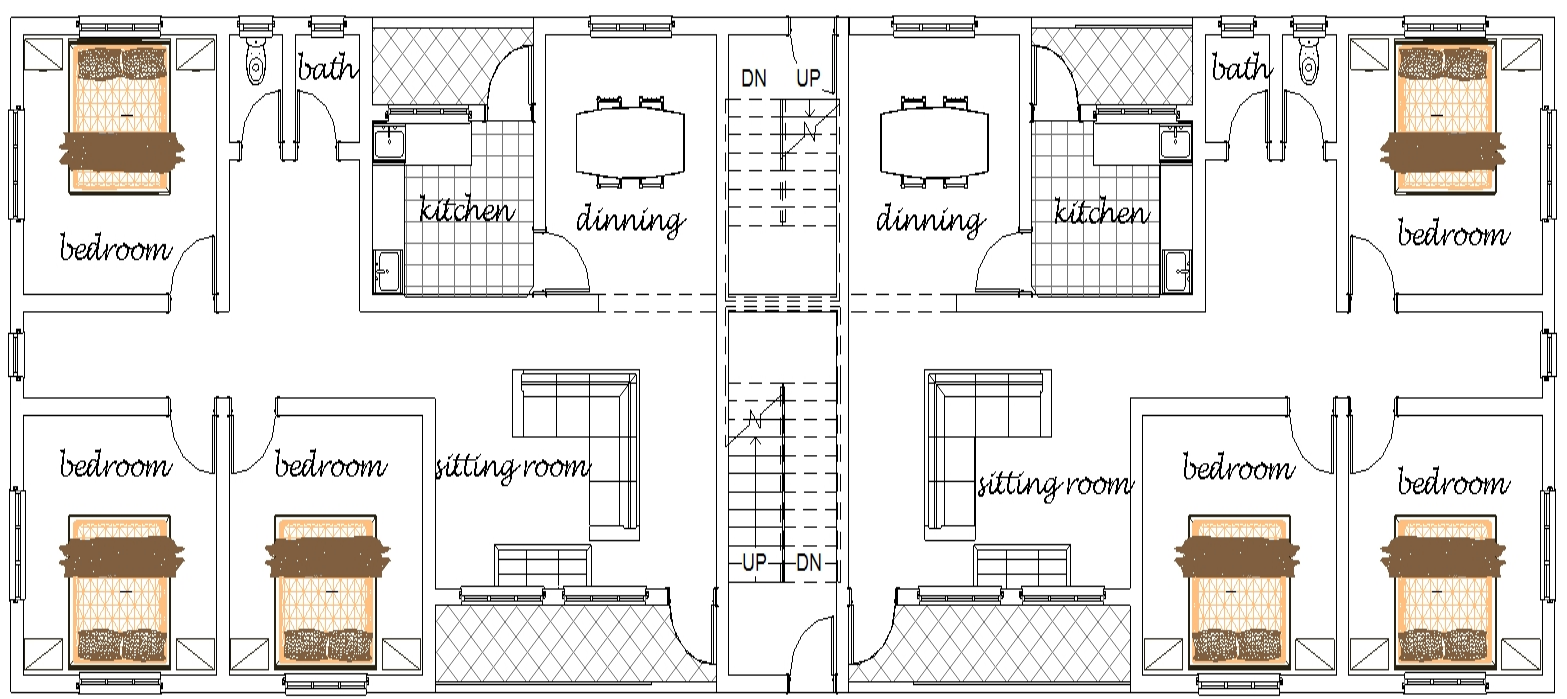

Figure 3. Floor Plan of Block of flats

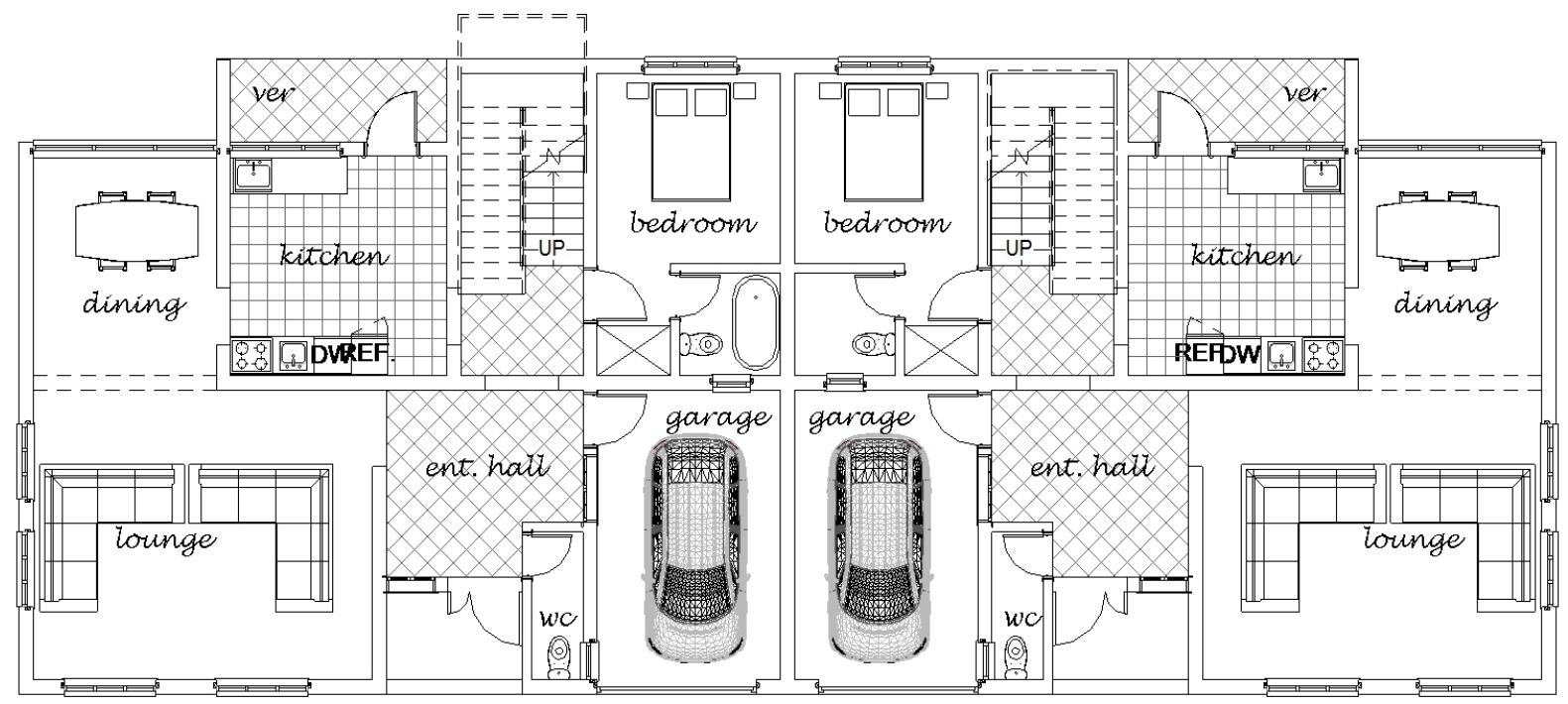

carport

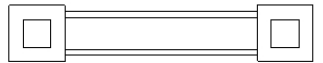

carport

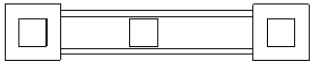

Figures 4. Ground floor plan of semi-detached maisonette with garages 


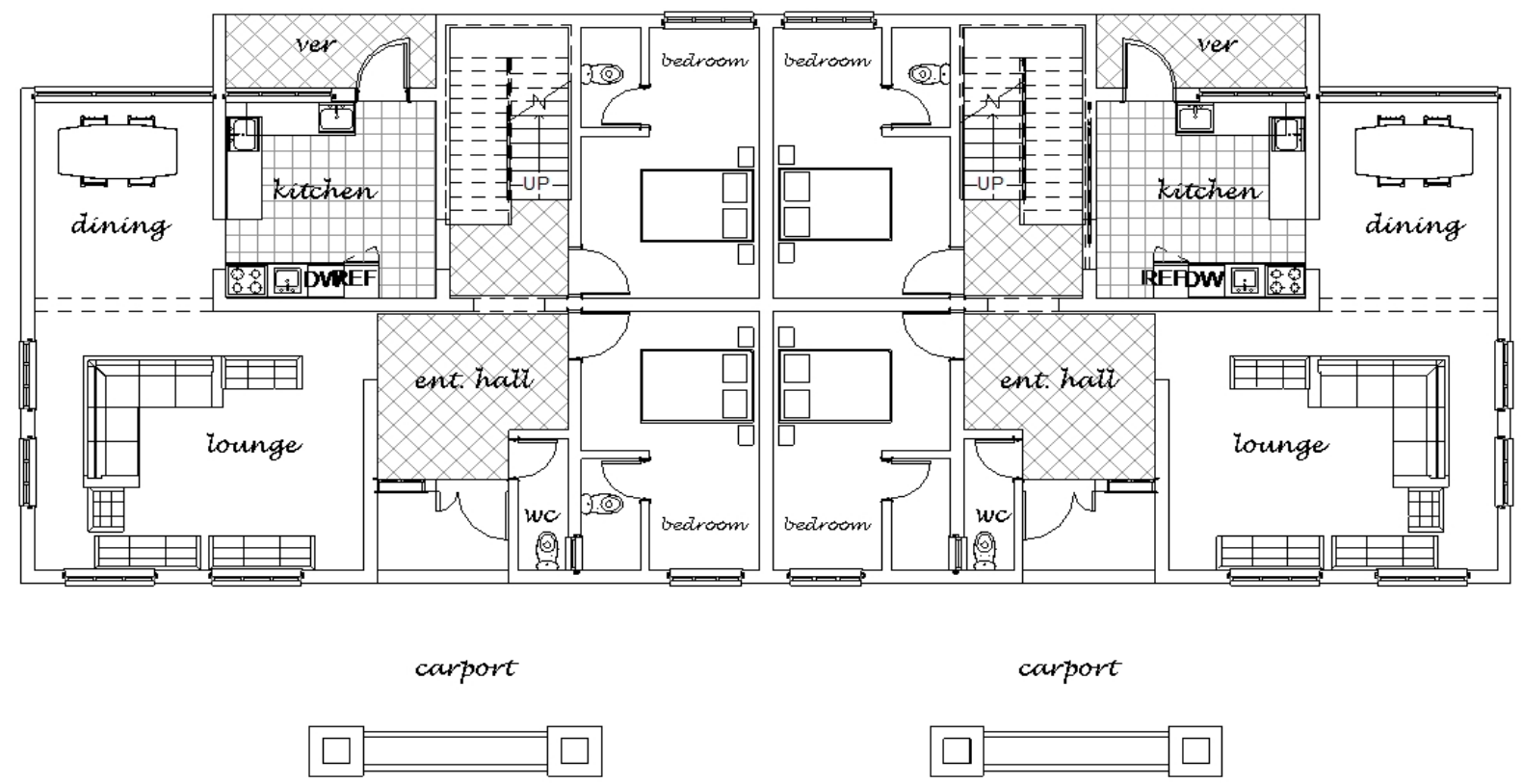

Figures 5. Ground floor plan of semi-detached maisonette without garages

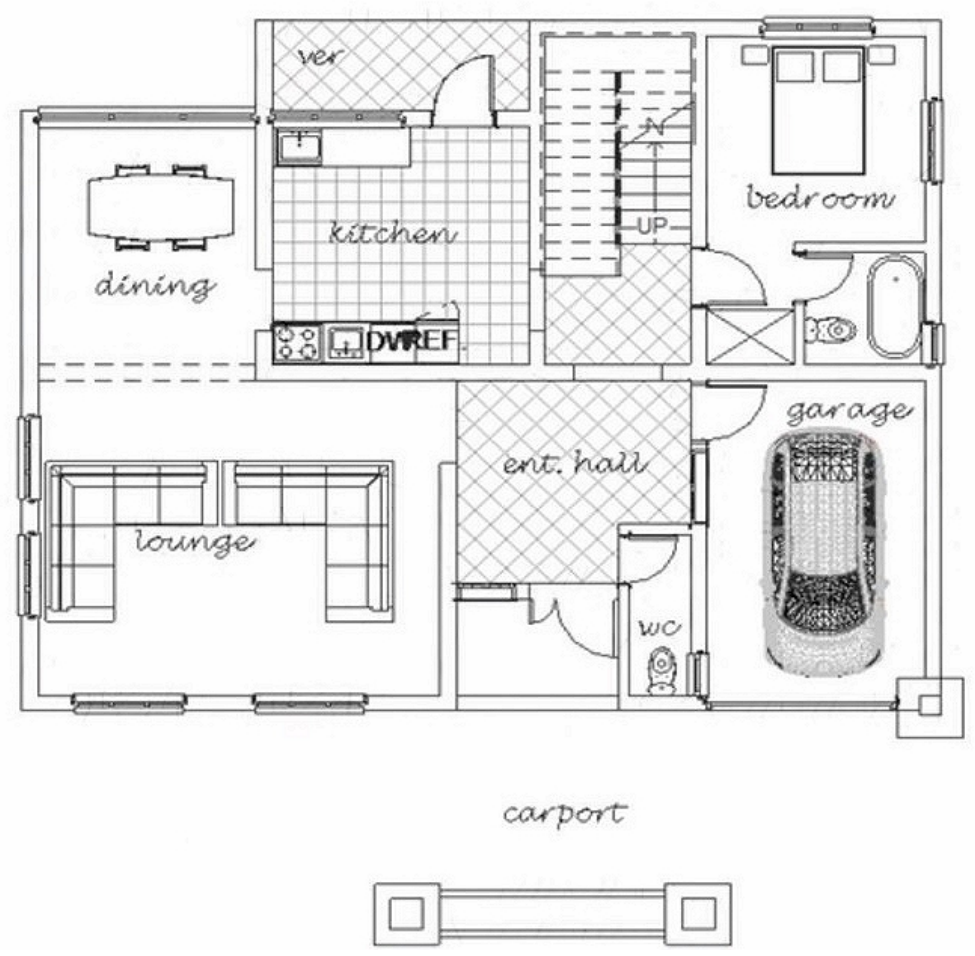

Figure 6. Ground floor of detached Maisonette with garage 


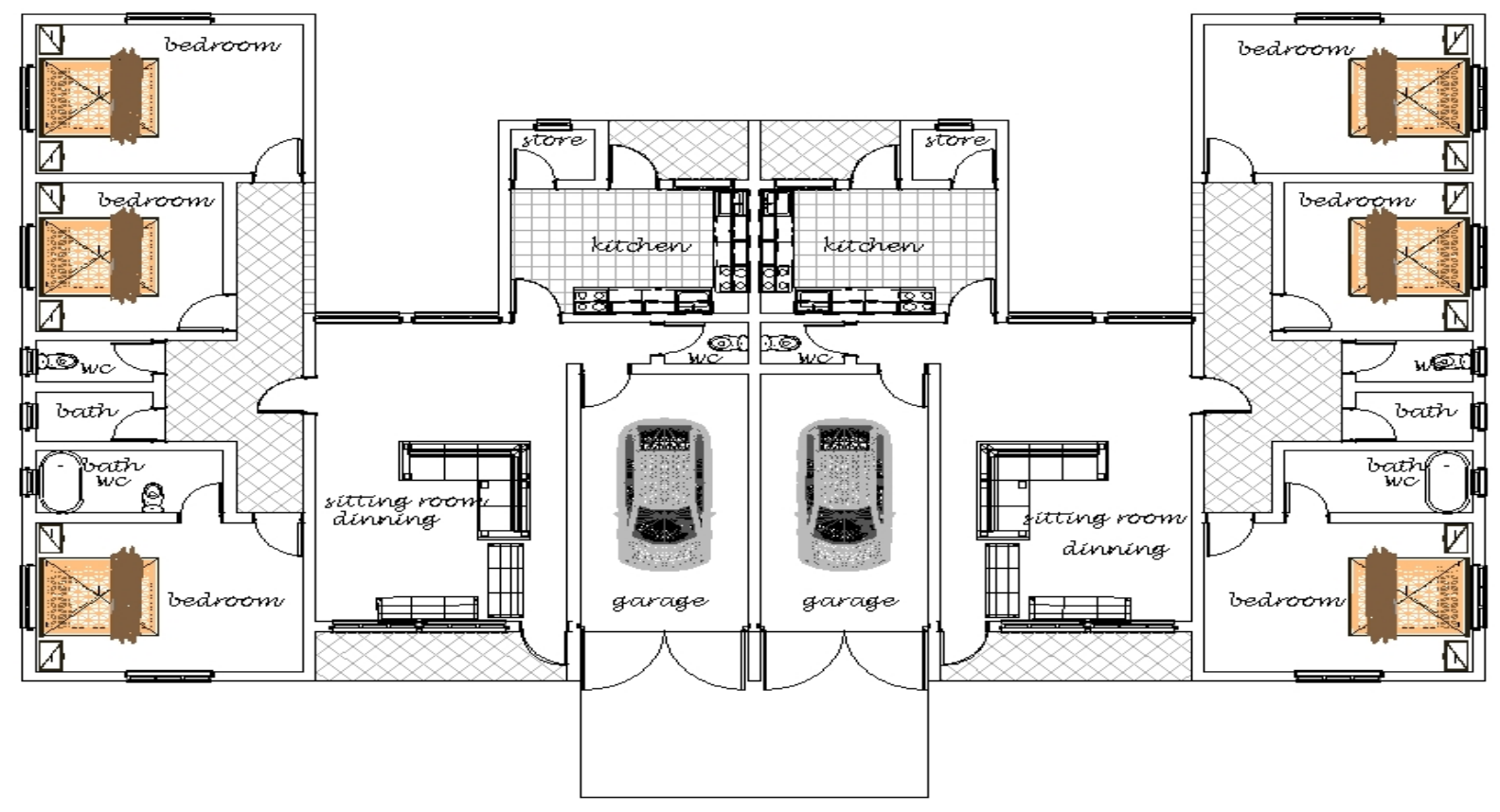

Figure 7. Floor plan of semi-detached bungalow with garage

Further examination of the floor plans of the buildings reveals that for the block of flats (Figure 3) and semi-detached bungalow with garage (Figure 7), the bathrooms and toilets are separated from the bedrooms and shared by the occupants, while stair cases are available for occupants to access the higher floor. These suggest that occupants have to move from their respective rooms to use these facilities thereby encouraging physical activity. The only different is that there are no stairs in the bungalow as they are not needed. Contrary to what is obtained in the semi-detached maisonette with garage (Figure 4), semi-detached maisonette without garage (Figure 5) and single maisonette with garage (Figure 6), the bathrooms and toilets are located in the bedrooms with wardrobes at close proximity to these facilities. These may discourage movement of the occupants in these residences. However, the presence of staircase to access the next floors of the buildings and lobbies to access the different spaces within the buildings are notable features identified in the literature as vital active design elements in buildings [22,26].

\subsection{Sedentary Behaviour and Physical Activity among the Residents in Different Housing Types}

Table 3 shows the results of sedentary behavior and physical activity of residents in the selected dwelling units. It is evident from these results that the residents sampled usually spend more time sitting at home (280.18mins) which amount to $90 \%$ of the total time they spent at home before going to bed (Table 3). They also spent an average of 22 minutes standing which is $5 \%$ of the total time they spent at home before bed and spend just $3 \%$ of the total time at home performing moderate activity. These results general indicate that the residents usually spend about $90 \%$ of their time at home sitting, which is a key sedentary activity. These results seem to provide support to the assertion by Wolin et al. [5] suggesting that adults, whether at home, work or school spend approximately between $50 \%$ and $60 \%$ of their day engaged in sedentary activities. In fact, evidence from this study indicates that the occupants encountered in the survey spend more than $60 \%$ of the time at home on sedentary activity.

Table 3. Sedentary behaviour and physical activity among residents

\begin{tabular}{|c|c|c|}
\hline & Mean \pm SD & \% Change \\
\hline Sedentary activity (Sitting) & $280.18 \pm 73.50$ & $90 \%$ \\
\hline Light activity (Standing) & $22.49 \pm 7.64$ & $7 \%$ \\
\hline Moderate Activity & $8.26 \pm 2.33$ & $3 \%$ \\
\hline
\end{tabular}

Table 4 shows that average time spent by the residents in different building types on physical activity was significantly different $(\mathrm{p}<0.001)$. A careful examination of the results reveals that the residents in maisonette building plan spent significantly longer time sitting (290.39 minutes), followed by residents in block of flats (284.16minutes), bungalow (274.36mins), and traditional building plans (237.52minutes) in that order. In contrast, those in the residential buildings designed in line with the traditional house layout spent the highest time (65.11 minutes) standing, while those in the maisonette spent the least amount of time (9.27minutes) in light activity such as standing. Similarly, moderate activity was only performed by residents in bungalow and building with the floors plans based on the traditional house layout spending significantly higher time on moderate activity ( $p$ $<0.001)$. Arguably, the key physical activity engaged in 
by the residents is associated with home-related activities such as eating, using the toilet, cooking, receiving visitors, walking to the gate and opening the door, using the staircase, bathing and others. The time spent on each of these activities depends mostly on the design the proximity of the spaces to each other, the nature of the circulation routes connecting them and the specific nature of each activity.

The results in Table 4 can be explained based on the earlier observations indicating that in the maisonette building types (Figures 4-6), the bedrooms have toilets and bathrooms and wardrobes within them at close proximity, which reduces the time occupants spend in accessing these facilities. In addition, as noted earlier, the buildings based on the traditional house layout have their main activity areas such as living and sleeping spaces separated from the toilets and bathrooms using courtyards and corridors. These features identified with the dwellings units designed based on the traditional house layout seem to be in agreement with the submissions of previous authors on the dynamics of spaces and fluidity and movement inherent in the traditional houses of the study area $[1,55]$. This seems to also resonate with the goal of active design, which is to encourage physical activity at home as explained in the literature [26]. Again, this may provide support to the submission of previous authors that the distance required to reach key destinations in residential buildings such as bed rooms, living rooms, kitchen, washrooms and others could affect occupants' sedentary lifestyle [24,25].

Table 5 shows that average time spent by the residents in different home features on physical activities (sitting and standing) was significantly different $(\mathrm{p}<0.05)$. The results of Duncan multiple comparison test revealed that residents in the dwelling units where the conveniences were separated from the sleeping place or lounge spent significantly lower time on sedentary activity, particularly, sitting $(F=8.411, p=0.001)$. The reverse was the case for light activity (standing), $(\mathrm{F}=6.178, \mathrm{p}=0.001)$. However, moderate activity was performed by residents with either detached or grouped convenience and this was statistically significant $(\mathrm{F}=7.211, \mathrm{p}<0.001)$.

Table 4. Comparison of mean time spent on physical activity by residents living in different type of space layout plan.

\begin{tabular}{|c|c|c|c|c|c|c|}
\hline \multirow[b]{2}{*}{ Intensity level (min/day) } & \multicolumn{4}{|c|}{ Building type } & \multirow[b]{2}{*}{$\mathrm{F}$} & \multirow[b]{2}{*}{$P$ value } \\
\hline & $\begin{array}{l}\text { Maisonette } \\
\text { Mean } \pm \text { SD }\end{array}$ & $\begin{array}{c}\text { Flat } \\
\text { Mean } \pm \text { SD }\end{array}$ & $\begin{array}{c}\text { Bungalow } \\
\text { Mean } \pm \text { SD }\end{array}$ & $\begin{array}{l}\text { Traditional } \\
\text { Mean } \pm \text { SD }\end{array}$ & & \\
\hline Sedentary activity (Sitting) & $290.39 \pm 73.33$ & $284.16 \pm 78.19$ & $274.36 \pm 67.84$ & $237.52 \pm 73.72$ & 9.551 & $<0.001$ \\
\hline Light activity (Standing) & $9.27 \pm 1.11$ & $14.01 \pm 2.63$ & $20.77 \pm 4.56$ & $65.11 \pm 8.36$ & 5.808 & 0.001 \\
\hline Moderate activity & - & - & $8.52 \pm 1.66$ & $20.57 \pm 3.82$ & 614.547 & $<0.001$ \\
\hline
\end{tabular}

Table 5. Comparison of mean time spent on physical activity by residents in different home space and features.

\begin{tabular}{|c|c|c|c|c|}
\hline $\begin{array}{l}\text { Intensity level } \\
\text { (min/day) }\end{array}$ & Home features & Mean \pm SD & $\mathbf{F}$ & P-value \\
\hline \multirow{5}{*}{$\begin{array}{l}\text { Sedentary Activity } \\
\quad \text { (Sitting) }\end{array}$} & $\begin{array}{l}\text { Sleeping space, TV lounge/study, in-suit toilet/dressing/wardrobe } \\
\text { with in-house private lounges, breakfast nooks / kitchen }\end{array}$ & ${ }^{\mathrm{a}} 321.20 \pm 76.63$ & & \\
\hline & Sleeping space, lounge, in-suit toilet/ wardrobe & a320.92 \pm 51.89 & 8.411 & 0.001 \\
\hline & Sleeping space, in-suit toilet, wardrobe & a $319.82 \pm 98.18$ & & \\
\hline & Sleeping space, wardrobe, grouped convenience & $242.36 \pm 45.61$ & & \\
\hline & Sleeping space, separated from bath and wc, non-purposive wardrobe & $221.12 \pm 54.76$ & & \\
\hline \multirow{5}{*}{$\begin{array}{l}\text { Light Activity } \\
\text { (Standing) }\end{array}$} & \begin{tabular}{|c|}
$\begin{array}{c}\text { Sleeping space, TV lounge/study in-suit toilet/dressing/wardrobe, } \\
\text { with in-house private lounges, breakfast nooks / kitchenette }\end{array}$ \\
\end{tabular} & ${ }^{\mathrm{a}} 11.01 \pm 2.04$ & & \\
\hline & Sleeping space, lounge, in-suit toilet/ wardrobe & ${ }^{\mathrm{a}} 11.92 \pm 2.45$ & 6.178 & 0.001 \\
\hline & Sleeping space, in-suit toilet, wardrobe & ${ }^{\mathrm{a}} 12.69 \pm 4.62$ & & \\
\hline & Sleeping space, wardrobe, grouped convenience & $21.52 \pm 7.42$ & & \\
\hline & Sleeping space, separated from bath and w.c, non-purposive wardrobe & $50.55 \pm 10.11$ & & \\
\hline \multirow{5}{*}{ Moderate Activity } & \begin{tabular}{|c|}
$\begin{array}{c}\text { Sleeping space, TV lounge/study, in-suit toilet/dressing/wardrobe, } \\
\text { with in-house private lounges, breakfast nooks / kitchen }\end{array}$ \\
\end{tabular} & - & & \\
\hline & Sleeping space, lounge, in-suit toilet/ wardrobe & - & & \\
\hline & Sleeping space, In-suit toilet, wardrobe & - & & \\
\hline & Sleeping space, wardrobe, grouped convenience & $11.12 \pm 1.77$ & 7.211 & $<0.001$ \\
\hline & Sleeping space, separated from bath and w.c, non-purposive wardrobe & $15.38 \pm 2.54$ & & \\
\hline
\end{tabular}

\footnotetext{
${ }^{\mathrm{a}}$ Duncan multiple comparison indicating means not significantly different
} 
The results in Table 5 further provide support to the result in Table 4 showing that residents in the buildings with traditional house layout pattern where there is separation of the main activities areas such as living/lounge, dining, kitchen and bedrooms from toilets and bathrooms, engaged more in physical activity (standing and movement) than those having these facilities en-suit. This is in line with the features of active design as presented in the literature $[23,26,48]$ and that submission by the UK's Design Council [39] indicating that the presence of stairs and location of spaces that encourage brief bouts of walking are key active design interventions.

\section{Conclusions and Recommendations}

This study explored the spatial design of residential building types and its influence on sedentary lifestyle of the occupants in Enugu metropolis in southeast Nigeria. Based on the findings of this research, the following conclusions and recommendations were arrived at. First, it can be concluded that dwelling units in the study area are based on traditional house and modern (western) house layout patterns. Whereas, in the former, the main activity areas such as living and sleeping areas are separated from the kitchens, toilets and bathrooms by courtyards and corridors, in the later the bathrooms and toilet facilities are integrated within the living, sleeping and indoor cooking areas. Second, it can also be concluded that although the residents sampled in the survey spent around $90 \%$ of the time at home on sedentary activity such as siting, the layout of residential buildings patterned after the traditional house design concept encouraged more physical activity among the occupants than those patterned after the modern or western style house layout pattern.

The current study has no doubt revealed that a greater part of the periods the residents spend at home are spent in sitting or lying or relaxing. However, the findings suggest that residents in houses designed using the traditional layout pattern spent significantly higher time on moderate activity, which may be due to the flexibility of spaces, the nature and sizes of the links between them, which naturally discourage sedentary behaviour at homes. In view of this advantage of traditional house layout over the modern one, it is recommended that architects, engineers and housing developers consider the adoption of the traditional layout pattern in the design and planning of future of homes. By this, spaces such as toilets and bathrooms should be separated from living and sleeping areas with lobbies and corridors. Similarly, where possible, instead of carryout out cutting and filling to ensure a relatively flat terrain for building construction, steps should be introduced within buildings in line with the site terrain to show change of levels, especially in bungalows where staircases are not required. A part from providing the opportunity for residents to engage in movements and physical activity at home, these features will help in achieving improved public health among the population, especially, urban residents. Going by the deep-rooted acceptance of the modern layout of residential buildings, there could be massive opposition in the adoption of the traditional layout in housing design among clients in the study area. To circumvent this, massive awareness campaigns and mass education of the public on the adverse health implications of modern house design on sedentary behaviour and its attendant health consequences are needed. The role of professional associations involved in the design and construction of residential buildings in achieving this cannot be over emphasised.

The study also revealed that apart from the presence of stairs in the buildings with more than one floor and the provision of lobbies in the dwelling units, which the literature has identified as among the key features of active design in homes, other spaces such as fitness rooms and utility lobbies that encourage physical activity at home were not provided in the residential buildings sampled. In view of these inadequacies, it is recommended that architects and engineers involved in house design and development should consider these spaces as vital components of homes, which prospective clients should pay for in their housing development projects. This will among other things ensure that architecture and engineering do not only provide residential buildings that shelter from inclement weather conditions and provide security from wild animals but they also contribute to residents' positive behavioral pattern and health needs by engaging in active design and construction of domestic spaces.

Although this research can be considered to have achieved its goal, the findings are limited to the biases of the residents who participated in the survey. The study is also limited to the nine out of the 24 residential neighbourhoods in Enugu metropolis; and thus the findings cannot be generalized for the remaining neighbourhoods excluded in the current research. Consequent upon these, future research is needed to include the other neighbourhoods and more participants in the study area and beyond for a more robust results that can be generalized beyond the geographic scope of the current research. Further, more research is required to defy the general rules and guidelines regarding the best practice in the design and planning of residential buildings capable of reducing the chronic diseases and non-communicable diseases associated with sedentary lifestyle of the people in different economic conditions, ethnic origins and cultures.

\section{REFERENCES}

[1] A.M. Ezezue, J.O. Diogu. Design strategies reduction of moisture in residential buildings in Enugu Nigeria. Tropical 
Built Environmental Journal, Vol1, No. 5, pp. 138-141, 2016

[2] European Commission press release Indoor air pollution: new EU research reveals higher risks than previously thought. Retrieved from http://europa.eu/rapid/press-releas e_IP-03-1278_en.htm/. 2003

[3] World Health Organization. Global recommendations on physical activity for health. Geneva: World Health Organization, 2010

[4] C.O. Odum, A.M. Ezezue. Health implications of conventional planning/design strategies on occupants of contemporary residential buildings in the hot-humid tropical environment. Journal of Housing and the Built Environment. 2020.https://doi.org/10.1007/s10901-020-09 769-x.

[5] Y. Wolin, L. Colditz. Physical activity and colon cancer prevention: a meta-analysis. Br. J. Cancer Vol 100, No.4, pp.611-616, 2019.

[6] R. R, Pate, J.R. O’Neill, F. Lobelo. The Evolving Definition of 'Sedentary'. Exer Sport Sci Rev, Vol.36, No. pp.173-178, 2008. Doi: 10.1097/JES.0b013e3181877d1a.

[7] C. Waters, E. Ling, A. Chu, S. Ng, A. Chia, Y. Lim, F. Müller-Riemenschneider. Assessing and understanding sedentary behaviour in office-based working adults: a mixed-method approach. BMC Public Health, Vol.16, No.360, pp. 1-11, 2016. doi 10.1186/s12889-016-3023-z.

[8] S. Parry, L. Straker. The contribution of office work to sedentary behaviour associated risk. BMC Public Health, Vol. 13, No. 296, pp.1-10, 2013. doi:10.1186/1471-2458-1 3-296.

[9] Lee, 1., Shirioma, E.J., Lobel, F., Puska, P., Blair, S. N., et, al., (2012). Effects of physical activity on major non-communicable diseases worldwide. An analysis of burden of disease and life expectancy. The Lancet, 380, 219-29. Doi: 10.1016/50140-6736(12) 61031-9.

[10] O.O. Ogwumike, B. Kaka, O. Adegbemigun, T. Abiona. Health-related and socio-demographic correlates of physical activity level amongst urban menopausal women in Nigeria. Maturitas, Vol. 73, pp. 349-353, 2012. https://doi.org/10.1016/j.maturitas.2012.09.010.

[11] A. Oyeyemi, O. Adeyemi. Relationship of physical activity to cardiovascular risk factors in an urban population of Nigerian adults. Archives of Public Health, Vol. 71, No. 6, pp.1-9, 2013. Doi: 10.1186/0778-7367-71-6.

[12] K.I Proper, A.S. Singh, W. van Mechelen, M. J. M. Chinapaw. Sedentary behaviours and health outcomes among adults: A systematic review of prospective studies. Am J Prev Med, Vol. 40, pp.174-182, 2011. Doi: 10.1016/j.amepre.2010.10.015.

[13] World Health Organization. Global recommendations on physical activity for health. World Health Organization, Geneva, 2010.

[14] K. Olayinka, A. Soyibo, T. Atinmo T. Impact of globalization on food consumption, health and nutrition in Nigeria. In Globalization of food systems in developing countries: impact on food security and nutrition. Paper 83 . Food and Agricultural Organization of the United Nations.2004. http://ftp.fao.org/docrep/fao/007/y5736e/y5736e00.pdf. December 19, 2010.

[15] O. Adediran, A.A. Akintunde, A.E. Edo, O.G. Opadijo, A.M. Araoye AM. Impact of urbanization and gender on frequency of metabolic syndrome among native Abuja settlers in Nigeria. J Cardiovascular Dis Res, Vol.3, pp.191-196, 2012. Doi: 10.4103/0975-3583.98890

[16] A. Oyeyemi, O. Adeyemi. Relationship of physical activity to cardiovascular risk factors in an urban population of Nigerian adults. Archives of Public Health, Vol. 71, No. 6, pp.1-9, 2013. Doi: 10.1186/0778-7367-71-6.

[17] Austine Ezezue, Eziyi Ibem, Chinwuba Odum, Bons Obiadi, "Architectural Design Interventions for Sedentary Behaviour among Workers in Office Buildings in Enugu, Nigeria," Civil Engineering and Architecture, Vol. 8, No. 6, pp.- 1462, 2020. DOI: 10.13189/cea.2020.080627

[18] Elizabeth Garland, Victoria Garland, Dominique Peters, John Doucette, Erin Thanik, Sritha Rajupet, Sadie H. Sanchez (2018). Active design in affordable housing: A public health nudge. Preventive Medicine Report, Vol. 10, pp. 9-14. https://doi.org/10.1016/j.pmedr.2018.01.015.

[19] R. Suminski, R. Petosa, E. Stevens, E.A method for observing physical activity on residential sidewalks and streets. J. Urban Health Vol.83, No. 3, pp. 434-443, 2016.

[20] F. Kerr, F., Eves, D. Caroll, D. Six-month observational study of prompted stair climbing. Am. J. Prev. Med. Vol.33, pp. 422-427, 2001.

[21] F. Nicol. Adaptive thermal comfort standards in hot humid tropics, Energy and buildings, Volume 36, No.7, pp. 628-637, 2004.

[22] D. Burney, A. Claffin, A. Practical considerations for implementing research on the built environment. Building research and information vol. 44, No.3, 342-344, 2016. http://dx.doi.org/10.1080/09613218.2015.1088225.

[23] L. Roux, M. Pratt, T.O. Tengs et al. Cost effectiveness of community-based physical activity interventions. Am J Prev Med Vol.35, pp. 578-88, 2008.

[24] E. Garland, A. Watts, J. Doucette J, et al. Stand up to work: assessing the health impact of adjustable workstations. Intl J of Workplace Health Mgt 2018; 11, pp.85-95, DOI: 10.1108/IJWHM-10-2017-0078.

[25] Center for Active Design. Active by design: Designing places for healthy lives. A short guide, 2010. Retrieved June 30, 2020, from http://www.designcouncil.org.uk/sites/defa ult/files/asset/document/Active_By_Design_Brochure_we b_LATEST.pdf.

[26] G. Samitz, E. Matthias, M. Zwahlen. Domains of physical activity and all-cause mortality: systematic review and dose response meta-analysis of cohort studies. Int. J. Epidemiol. Vol. 40, No. 5, pp. 1382-1400, 2011. doi: 10.1093/ije/dyr112.

[27] J. Sattlemair, J. Pertman, E. Ding, H. Kohl, W. Haskell, I. Lee, I. Dose response between physical activity and risk of coronary heart disease: a meta-analysis. Circulation, Vol. 124, No. 7. Pp. 789-795, 2011.

[28] City of New York. Active Design Guidelines: Promoting Physical Activity and Health in Design, 2010. Retrieved on 
July 6, 2020 from http://centerforactivedesign.org/dl/guide lines.pdf/

[29] J.P. Buckley, A, Hedge, T. Yates, R.J. Copeland, M. Loosemore, M. Hamer, D.W. Dunstan. The sedentary office: a growing case for change towards better health and productivity. British Journal of Sports Medicine. Vol. 49, No 21, pp.1357-62, 2015.Doi:10.1136/bjsports-2015-0946 18.

[30] L.B. Dugdill, A. Hulme, C. McCluskey, S. A.F. Long. Workplace physical activity interventions: a systematic review. Int J Workplace Health Manage. Vol 1, No.1 pp. 20-40, 2008. Doi.org/10.1108/17538350810865578.

[31] C. Marcela, Impact of Workplace Design and Planning on Sedentary Lifestyles. A Thesis Presented to the Faculty of the Graduate School of Cornell University in Partial Fulfilment of the Requirements for the degree of Master of Science, 2018.

[32] L. Smith, M. Ucci, A. Marmot et al. Active buildings: modelling physical activity and movement in office buildings. An observational study protocol. BMJ Open Pp.1-7, 2013. doi:10.1136/bmjopen-2013- 004103

[33] Centers for Disease Control and Prevention. Adult participation in aerobic and muscle-strengthening physical activities - United States. Morbidity and Mortality Weekly Report, Vol. 62, No. 17, pp.326-329, 2013.

[34] City of New York. Active Design Guidelines: Promoting Physical Activity and Health in Design, 2010. Retrieved on July 6, 2020 from http://centerforactivedesign.org/dl/guide lines.pdf/.

[35] J.F. Sallis, J. Measuring Physical Activity Environments. American journal of preventive medicine. 2010 Retrieved February 15, 2021 from https://www.ncbi.nlm.nih.gov/pm c/articles/PMC2921817/

[36] World Health Organization. World Health Organization Global Action Plan on Physical Activity 2018 - 2030 - More Active People for a Healthier World, 2018.

[37] A. Marmot, M. Ucci. Sitting less, moving more: the indoor built environment as a tool for change. Building research and information. Vol. 43. No 5, pp. 561-565, 2015 $\mathrm{http} / /$ dx.doi. org/10.1080/09613218.069081.

[38] UK's Design Council (2014) Active by Design: Designing places for healthy lives. Retrieved on March 23, 2021 from https://www.designcouncil.org.uk/sites/default/files/asset/d ocument/Active_By_Design_Brochure_web_LATEST.pdf

[39] L. Smith, U. Ekelund, M. Hamer. The Potential yield of non-exercise physical activity energy expenditure in public health, Vol. 45, No.4, pp. 449-452. 2015 doi: 10.1007/s 40279-015-3010-2.

[40] K. Brookfield, C. Fitzsimons, I Scott, G. Mead, J. Starr, N. Thin, A. Tinker, C.A. Thompson, C.A. The home as enabler of more active lifestyles among older people, Building Research \& Information, Vol.43, No 5, Pp. 616-630, 2015 DOI: $10.1080 / 09613218.2015 .1045702$

[41] D. Barnett, A. Barnett, A. Nathan, J. Van Cauwenberg, E. Cerin. Built environmental correlates of older adults' total physical and walking: a systematic review and meta-analysis. Int. J. Behav. Nutr. Phys. Act Vol. 14, No. 1, pp.103-110, 2017. doi:10.1186/s12966-017-0558-z.

[42] S. L. Handy, M. G. Boarnet, R. Ewing, R. E Lillingsworth How the built environment affects physical activity: views from urban planning. Am. J. Prev. Med. 30, pp. 277-281, 2002. https://doi.org/10.1016/S0749-3797(02)00475-0.

[43] Centers for Disease Control and Prevention, (2015b). Physical activity and health. Retrieved on 22 March 2021 from

https://www.cdc.gov/physicalactivity/basics/pa-health/inde x.htm.

[44] C. Zimring, A. Joseph, G.I. Nicoll, S. Tsepas. Influences of building design and site design on physical activity. American Journal of preventive medicine, Vol 28, pp. 186-193, 2005. doi: 10:1016/j.ampre. 2004.10.025.

[45] N. Owen, L. J. Salmon, J., M.J. Fotheringham. Environmental determinants of physical activity and sedentary behaviour. Exercise and Sports Sciences Reviews, Vol.28, No.4, pp. 153-158. 2000.

[46] R. Ewing Can the physical environment determine physical activity levels? Exercise and Sport Science Reviews, Vol. 33 , No. 32, pp. $69-75,2005$. DOI: $10.1097 / 00003677-2005$ 04000-00003.

[47] L.D. Frank. T.L. Schmid, J.F Sallis, J. Chapman, B.E. Saelens, B.E. Linking objectively measured physical activity with objectively measured urban form: Findings from SMARTRAQ. American Journal of Preventive Medicine, Vol 28, Suppl. 2, pp. 117- 125, 2005.

[48] A.M. Ezezue, E.O. Ibem, E.I. Kikanme, E.I. Safety Rest Areas and Fatigue Related Road Accidents in Enugu, Nigeria. International Journal of Innovative Technology and Exploring Engineering, Vol.8 No.8, pp. 1137-1144, 2019.

[49] Enugu State Government. Geographical Location/Demogr aphy of Enugu., 2019. Retrieved on 23 March 2021 from https://www.enugustate.gov.ng/index.ph p/elements-devices/

[50] National population Commission. Official gazette for the National Population and Housing Survey, Nigeria, Abuja, 2006.

[51] V. U, Okwu-Delunzu, F. Iloeje, C. Aniagolu. Assessment of climate change on Enugu urban environment using temperature and rainfall information. IJSAR Journal of Environmental, Earth and Physical Sciences, Vol.2, No.1, Pp.38-49, 2015.

[52] W.G. Cochran. Sampling Technique. 2nd Edition, John Wiley and Sons Inc., New York, 1963.

[53] E.E. Ezenwaji, C.P. Nzoiwu, B.M. Eduputa. Enhancing Urban Water Supply through Rainwater Collection in Enugu Town, Nigeria. Journal of Geoscience and Environment Protection, Vol. 4, pp.82- 88. 2016. http://dx.doi.org/10.4236/gep.2016.42010.

[54] C. Aniako. Igbo Architecture in A survey of the Igbo Nation. Africana First Publishers, 2002.

[55] Z. Dmochowski. An Introduction to Nigerian Traditional Architecture. Jolly \& Barber Ltd. 1990. 